\title{
Development of a Novel Cell Encapsulation System Based on Natural Origin Polymers for Tissue Engineering Applications
}

\author{
S. M. LunA, ${ }^{1,2}$ M. E. GOMES, ${ }^{1,2}$ J. F. MANO ${ }^{1,2, *}$ AND R. L. REIS ${ }^{1,2}$ \\ ${ }^{1}$ Biomaterials, Biodegradables and Biomimetics, University of Minho \\ Headquarters of the European Institute of Excellence on Tissue Engineering \\ and Regenerative Medicine, AvePark, 4806-909 Taipas, Guimarães, Portugal \\ ${ }^{2}$ Institute for Biotechnology and Bioengineering, PT Government Associated \\ Laboratory, Braga, Portugal
}

\begin{abstract}
Cells microencapsulated in biocompatible semi-permeable polymeric membranes are effective as cell delivery systems while protecting the host against immune responses. In this study, cell encapsulation membranes were prepared based on carrageenan and alginate, two natural cationic polymers. Different formulations/conditions were explored to optimize the microcapsules which were characterized with respect to their morphology, mechanical stability, and cytotoxicity. Spherical-shaped microcapsules were obtained from all the polymeric systems. The iota-carrageenan/sodium alginate microcapsules exhibited the best stability and permeability, and therefore, these were selected for the cell encapsulation. These capsules provided an environment that supported cell proliferation and have the potential for tissue engineering as well as other cell-based therapy applications.
\end{abstract}

KEY WORDS: capsules, carrageenan, alginate, fibroblasts, cell viability.

\section{INTRODUCTION}

A $\mathbf{n}$ effective method of immunoprotecting cells and proteins for A implantation into unmatched recipients, as well as delivery via

*Author to whom correspondence should be addressed. E-mail: jmano@dep.uminho.pt Figures 1-7 and 10 appear in color online: http://jbc.sagepub.com

Journal of BIOACTIVE AND COMPATIBLE POLYMERS, Vol. 25-July 2010

0883-9115/10/04 0341-19 \$10.00/0～DOI: 10.1177/0883911510372173

(C) The Author(s), 2010. Reprints and permissions:

http://www.sagepub.co.uk/journalsPermissions.nav 
injection into a target defect, is encapsulation [1]. The polymers and procedures used for encapsulation are especially important for tissue engineering applications [2]. Several polymers have been studied for microcapsule formation, such as agarose, alginate, polyacrylates, poly(vinyl alcohol), chitosan, and poly(L-lysine) [3,4], with the objective of enhancing and optimizing the cell immobilization by maintaining the general cell functions and survival rates [5,6]. It is important to obtain biocompatible and semi-permeable polymeric membranes that allow molecular transport and cell survival within the capsules [7].

This study describes the combination of two natural polymers, iotacarrageenan and sodium alginate (both polyanions), for encapsulating living cells. Carrageenans form helical structures with the ability to form gels at room temperature [8]. Their main chain consists of alternating copolymers of $1,4-\beta$ and $1,3-\alpha$-D-galactopyranose as well as 3,6 -anhydro-D-galactopyranose. The main structural differences in the three different types of carrageenans (iota, kappa, and lambda) is in the degree of sulfate substitution $[8,9]$. In the case of iota- and kappa-carrageenan, the chemical structure of iota-carrageenan differs from that of kappa-carrageenan by the presence of an additional sulfate group in the 3,6-anhydrogalactosyl residue, which confers a more hydrophilic character to the molecule $[10,11]$. Previous investigations have reported the development of capsules using carrageenan and oligochitosan polymer [8] for the encapsulation of microbial cells [12-14].

Alginate is composed of mannuronic (M) and guluronic (G) acids and is a commonly employed polysaccharide for cell encapsulation [15]. However, alginate capsules have poor mechanical stability and usually require further treatment with citrate to liquefy the core of the capsules to enable cell survival [15-18]. Chitosan is a linear polysaccharide produced by the deacetylation of chitin [19] used for a variety of powders, gels, porous structures, fibers, membranes, and films for biomedical applications [20-24].

The aim of this work was to combine the advantageous features of alginate with those of carrageenan and chitosan to form capsule membranes. Chitosan with its positive charges were interacted with the anionic alginate and carrageenan, to create a membrane at the capsule's surface, which could improve the mechanical stability of the structures [25]. Capsules, based on different formulations and conditions, were studied with respect to their morphology, mechanical stability, cytotoxicity, and ability to maintain the viability of encapsulated cells. 


\section{MATERIALS AND METHODS}

\section{Materials}

Iota-carrageenan (22045), kappa-carrageenan (22048), sodium alginate (71238), $\beta$-glycerophosphate disodium salt ( $\beta$-GP/G9891), phosphate buffer saline (PBS-P4417), sodium citrate (S1804), and DAPI (4'6diamidino-2-phenylindole/D9564) were purchased from Sigma (Portugal). Low molecular weight $(\mathrm{Mw})$ chitosan powder was obtained from Aldrich/448869 (Portugal). Calcein-AM (acetoxymethyl ester of calcein) was purchased from Invitrogen/C3099 (Portugal).

\section{Adjustment of the pH of the Chitosan Solutions with $\beta$-GP}

A solution containing $0.0266 \mathrm{~g} / \mathrm{mL}$ of $\beta$-GP was slowly added to a chitosan solution $(0.30 \%$ in $0.017 \mathrm{M} \mathrm{HCl})$ until physiological $\mathrm{pH} 7$ was obtained. At this point, precipitation occurs. A curve of the variation of the $\mathrm{pH}$ in chitosan solution as a function of $\beta$-GP concentration was developed to determine the amount of $\beta$-GP to be added to reach the desired $\mathrm{pH}$.

\section{Microcapsules Based on Iota- and Kappa-Carrageenan}

Capsules were obtained using chitosan solutions at two different $\mathrm{pHs}$, 5.0 and 6.0, adjusted with $\beta$-GP. The microcapsules were obtained by adding $1 \mathrm{~mL}$ of an $1.5 \%$ aqueous solution of iota (or kappa)-carrageenan dropwise through a $0.3 \mathrm{~mm}$ needle (BD-Microfine U-100 insulin, Portugal, using an AL-1000, Aladdin Programmable Syringe Pump) into $20 \mathrm{~mL}$ of an $0.15 \%$ chitosan in a solution at $0.0085 \mathrm{M} \mathrm{HCl}$. The capsules were allowed to harden for $45 \mathrm{~min}$ at $37^{\circ} \mathrm{C}$ in a water bath, washed with $0.9 \%$ $\mathrm{NaCl}$ and immersed in a $0.05 \%$ iota-carrageenan solution for $5 \mathrm{~min}$ in order to link the remaining residues of chitosan. The capsules were then rinsed twice with $\mathrm{PBS}$ and stored at $4^{\circ} \mathrm{C}$ in the same buffer.

\section{Sodium Alginate/Iota-carrageenan Microcapsules}

Aqueous alginate/iota-carrageenan mixtures composed of a $1.5 \%$ aqueous solution of each polymer, at two different ratios, 50/50 and $30 / 70(\mathrm{v} / \mathrm{v})$, were prepared as follows. A mixture of $1 \mathrm{~mL}$ was extruded using a $0.3 \mathrm{~mm}$ syringe into $20 \mathrm{~mL}$ solution of $0.05 \mathrm{M} \mathrm{CaCl}_{2}$ and 
$0.2 \mathrm{M} \mathrm{NaCl}$ in distilled water. The microcapsules were allowed to harden for $30 \mathrm{~min}$ at $37^{\circ} \mathrm{C}$. The capsules were then immersed in $20 \mathrm{~mL}$ of chitosan solutions ( $\mathrm{pH} 5.0$ and 6.0) prepared as described above for $20 \mathrm{~min}$ at $37^{\circ} \mathrm{C}$. The capsules were rinsed with PBS for $1 \mathrm{~min}$ and immersed in a $0.05 \%$ iota-carrageenan for $5 \mathrm{~min}$. Microcapsules with liquedied core were also prepared using sodium citrate. The obtained iota-carrageenan + alginate microcapsules obtained above were immersed in a $0.055 \mathrm{M}$ solution of sodium citrate for $1 \mathrm{~min}$ [5,26]. Immersion times $>1.5$ min disintegrated the liquefied capsules; therefore, 1 min was chosen for comparison with solid capsules. The obtained capsules (solid and liquefied) were rinsed twice with PBS buffer and stored at $4^{\circ} \mathrm{C}$ in the buffer for characterization. The capsules were immersed in Dulbecco's Modified Eagle's Medium (DMEM) to assess the stability of the microcapsules in culture medium and to observe the capsule permeability.

\section{Morphological Characterization of Microcapsules}

The size and shape of the microcapsules were examined by stereomicroscopy (Zeiss-Stemi 2000-C KL 1500 LCD, 459315) and with an inverted light microscope (Zeiss, Axiovert $40 \mathrm{CFL}, 459306)$. The capsules were stained in $0.1 \%(\mathrm{w} / \mathrm{v})$ eosin dye (eosin Y solution, alcoholic with phloxine B $0.1 \%(\mathrm{w} / \mathrm{v}) / \mathrm{HT} 110316$, Sigma-Aldrich, Portugal) to observe the membranes.

\section{Evaluation of Mechanical Stability}

Both the solid and partially liquefied microcapsules produced were submitted to a short-term stability evaluation assay and 50 capsules of each type were placed in 24 well plates (10 per well) with $800 \mu \mathrm{L}$ of PBS solution in each well. The culture plate was then agitated at $200 \mathrm{rpm}$ and $25^{\circ} \mathrm{C}$ for different periods of time, namely $1,3,6,24$, and $48 \mathrm{~h}$. The percentage of ruptured capsules, as a function of time, was determined by stereomicroscopy.

\section{Assessment of in vitro Cytotoxicity of the Developed Capsules}

To evaluate possible toxic effects of leachables from the microcapsules and polyanions used, MTT testing was used. Latex rubber (Dermagip, WRP) was used as a positive control and standard culture plates (Costar 96 well plate) were used as a negative control. Extracts of the capsules and the positive control were obtained by immersion in culture medium for $24 \mathrm{~h}$ at $37^{\circ} \mathrm{C}$ and $60 \mathrm{rpm}$. 


\section{Cell Culture}

A mouse lung fibroblast cell line (L929), obtained from European Collection of Cell Cultures (ECC, UK), was used for the cytotoxicity assays. The cells were grown as monolayer in $75 \mathrm{~cm}^{2}$ culture flasks, using DMEM-low glucose (DMEM-Sigma-Aldrich), supplemented with $10 \%$ fetal bovine serum (FBS), $1 \%$ antibiotic/antimycotic and sodium bicarbonate at $37^{\circ} \mathrm{C}$ in a $5 \% \mathrm{CO}_{2}$ incubator. Cells were harvested before reaching confluence from $75 \mathrm{~cm}^{2}$ culture flasks using trypsin-EDTA, and a cell suspension was prepared to obtain a cell density of $6.6 \times 10^{4}$ cells $/ \mathrm{mL}$. Cell suspension $(200 \mu \mathrm{L} /$ well $)$ was cultured in a 96 well culture plate in DMEM. After the cells were attached to the culture plate, the culture medium was replaced by $150 \mu \mathrm{L}$ of extracted capsules prepared in complete culture medium and incubated for 24,48 , and $72 \mathrm{~h}$ at $37^{\circ} \mathrm{C}$.

\section{Preparation of the Extracts}

The extracts were obtained by immersing 100 microcapsules (of each type) in a sterile tube containing $5 \mathrm{~mL}$ of DMEM and placed in a water bath at $37^{\circ} \mathrm{C}$ and $60 \mathrm{rpm}$ for $24 \mathrm{~h}$ and the extract filtered using a $0.45 \mu \mathrm{m}$ syringe filter. As a positive control, 60 squares of $1 \mathrm{~cm}^{2}$ of latex rubber were immersed in DMEM culture medium following the same procedure described for the tested materials.

\section{MTT Assay}

The MTT solution $(50 \mu \mathrm{L}$ of $1 \mathrm{mg}$ MTT/mL DMEM without phenol red) was added to the cell monolayers, previously exposed to extracts obtained from the capsules and incubated at $37^{\circ} \mathrm{C}$ in a $5 \% \mathrm{CO}_{2}$ incubator for $4 \mathrm{~h}$. The MTT solution was removed and replaced by $10 \mu \mathrm{L}$ of isopropanol to lyse the cells [27]. The solution became purple and the optical density (OD) was measured in a microplate reader (BIO-TEK Synergy HT) at $570 \mathrm{~nm}$, with a background correction of the OD at $650 \mathrm{~nm}$. The results were expressed as percentage of cell viability calculated using the following equation:

$$
\text { Cell viability }(\%)=\left(\mathrm{OD}_{\text {sample }} / \mathrm{OD}_{\text {control }}\right) \times 100
$$

where $\mathrm{OD}_{\text {sample }}$ is the OD obtained in the cells exposed to each extract/ capsule and $\mathrm{OD}_{\text {control }}$ the $\mathrm{OD}$ obtained in the cells incubated with the culture medium only (negative control) [28]. 


\section{Cell Encapsulation}

Immobilization of the cells was performed using a L929 fibroblasts cell line in sodium alginate/iota-carrageenan solid and liquefied capsules. Microcapsules and cell encapsulation procedures were carried out at room temperature under sterile conditions, using a laminar flow cabinet. All solutions were prepared in distilled water and filtered using a $0.2 \mu \mathrm{m}$ membrane filter (Schleicher \& Schuell Microscience, Germany). The sodium alginate, iota-carrageenan and chitosan solutions were autoclaved prior to use. The fibroblast cells were initially harvested from monolayer using trypsin-EDTA (Invitrogen, Portugal). A suspension containing $5 \times 10^{3}$ cells per $\mathrm{mL}$ of the polymeric solution were mixed with the sodium alginate/iota-carrageenan (30/70) solution. The cell-polymeric suspension was extruded into a calcium chloridesodium chloride $\left(\mathrm{CaCl}_{2}-\mathrm{NaCl}\right)$ solution, as described above using a syringe pump. The resulting microcapsules/cells were maintained in $\mathrm{CaCl}_{2}-\mathrm{NaCl}$ for $30 \mathrm{~min}$ at $37^{\circ} \mathrm{C}$ in a $5 \% \mathrm{CO}_{2}$ incubator. The capsules containing the cells were then immersed in $20 \mathrm{~mL}$ of chitosan solution (adjusted to $\mathrm{pH} 5.0$ with $\beta$-GP) for $10 \mathrm{~min}$ and at $37^{\circ} \mathrm{C}$ in a $5 \% \mathrm{CO}_{2}$ incubator. The capsules were rinsed with PBS for 1 min and immersed in $0.05 \%$ iota-carrageenan for $5 \mathrm{~min}$. To obtain the liquefied capsules, the microcapsules with cells were treated with $0.055 \mathrm{M}$ of sodium citrate for $1 \mathrm{~min}$. Finally, microcapsules with cells were washed twice with PBS, transferred to a 6 well culture plate and immersed in culture medium. The encapsulated cells were cultured in a $5 \% \mathrm{CO}_{2}$ incubator for different periods of time, $1,2,3$, and 7 days. The culture medium was changed every 2 days.

\section{Morphological Characterization in Encapsulated Cells}

The morphology of the microcapsules containing the cells as well as the morphology of the cells, were analyzed using inverted light microscopy and a stereomicroscopy, respectively. The viability of the encapsulated cells were assessed using the methylene blue staining.

\section{MTS Assay}

Cellular viability of entrapped fibroblast cells was determined using the MTS testing $[29,30]$. The microcapsules (30/70) containing cells (three capsules per well) were immersed in a culture medium containing MTS, in a 5:1 ratio, and incubated at $37^{\circ} \mathrm{C}$. After $3 \mathrm{~h}$ of incubation, $100 \mu \mathrm{L}$ of the solution obtained from each well (containing the encapsulated cells) were transferred to a 96 -well plate. The absorbance 
was read with a microplate reader (BIO-TEK - Synergy HT) at $490 \mathrm{~nm}$. An alginate/iota-carrageenan mixture (30/70) of fibroblasts cells was used as the control.

\section{Staining of Calcein-AM and DAPI Fluorescents}

Two fluorescent dyes were used to assess the cellular viability in encapsulated cells. Calcein-AM, a green dye, was used to identify the viable cells and DAPI, a blue dye, was used to identify cell nucleus in live and fixed cells. In this assay, the capsules were placed into an Eppendorf tube containing $1 \mathrm{~mL}$ of DMEM and $2 \mu \mathrm{L}$ of Calcein-AM and incubated for $20 \mathrm{~min}$ at $37^{\circ} \mathrm{C}$ in $5 \% \mathrm{CO}_{2}$. The capsules were then rinsed in DMEM culture medium and PBS solution. The PBS was replaced by $500 \mu \mathrm{L}$ of glutaraldehyde $(2.5 \%)$ for $10 \mathrm{~min}$ at room temperature to fix the cells. The excess glutaraldehyde was removed and the capsules were rinsed twice in PBS. A new PBS solution $(1 \mathrm{~mL})$ and $2 \mu \mathrm{L}$ of DAPI were added to the capsules and incubated for $20 \mathrm{~min}$ at $37^{\circ} \mathrm{C}$ in $5 \% \mathrm{CO}_{2}$. The capsules were rinsed twice in PBS and observed under a fluorescence microscope (Zeiss 434301) using Alexa Flour 488 and DAPI 49. All the procedures were performed in the dark.

\section{Statistical Analysis}

The results obtained in the mechanical stability tests and in the MTT (in vitro cytotoxicity of capsules' leachables) and MTS tests (as cellular viability of encapsulated cells) are presented as means \pm standard deviation. The statistical analysis of the results was performed using the Student's $t$-test, with a significance level of $95 \%(p<0.05)$.

\section{RESULTS AND DISCUSSION}

Microcapsules were formed as iota- or kappa-carrageenan complexes. Both carrageenans have polyelectrolytic character and form a thermoreversible gel, which is induced by selected monovalent and/ or divalent metal cations $[8,11]$. Based on stereomicroscope and inverted light microscope observations, the kappa- and iotacarrageenans formed spherical-shaped microcapsules with $2.0-2.2 \mathrm{~mm}$ diameters (Figure 1).

In this study, chitosan solutions, with different $\mathrm{pHs}$ were used to form different types of capsules by polyelectrolyte complex and ionotropic gelation method, since changes in the $\mathrm{pH}$ alters the protonation degree and bonding interactions in chitosan [31]. 
Previous studies have demonstrated that chitosan can be neutralized to physiological $\mathrm{pH}$ (7.2) using $\beta$-GP, without promoting the precipitation [31,32]. The capsules formed at $\mathrm{pH}$ 5.0, exhibited a smoother surface than the capsules formed at $\mathrm{pH}$ 6.0. At $\mathrm{pH}$ 5.0, the capsules have higher chitosan protonation that can induce a more homogeneous complex. These results are in accordance with alginate/oligochitosan and carrageenan/oligochitosan systems developed in other studies, where a more compact polyelectrolyte complex with higher crosslinking density was formed $[8,17,33]$.

The thickness and strength of the capsule wall were controlled by varying the $\mathrm{Mw}$ of the constituent polymers. The lower $\mathrm{Mw}$ forms diffuse through the capsule membrane more rapidly, thus produce thicker walls before being hampered by the diffusion distance. The lower Mw chitosan capsule walls are both thicker and less elastic than those made with higher $\mathrm{Mw}$ forms [34]. As a result, the diluted chitosan solution $(0.15 \%)$ used in the capsules developed produced a membrane with less elasticity but with fewer incidences of physical defects. Moreover, the low $\mathrm{Mw}$ chitosan increases its capacity to penetrate and interact with the core polymer [2].

In general, kappa-carrageenan generated thicker gels in the core as compared to iota-carrageenan (Figure 1), which might compromise the exchange of gases and nutrients, harming the viability of the encapsulated cells. Therefore, iota-carrageenan was selected for further studies, concerning the development of microcapsules based on the combination of this polymer with alginate. Previous studies [17] have demonstrated that iota-carrageenan and alginate are similar because both polymers

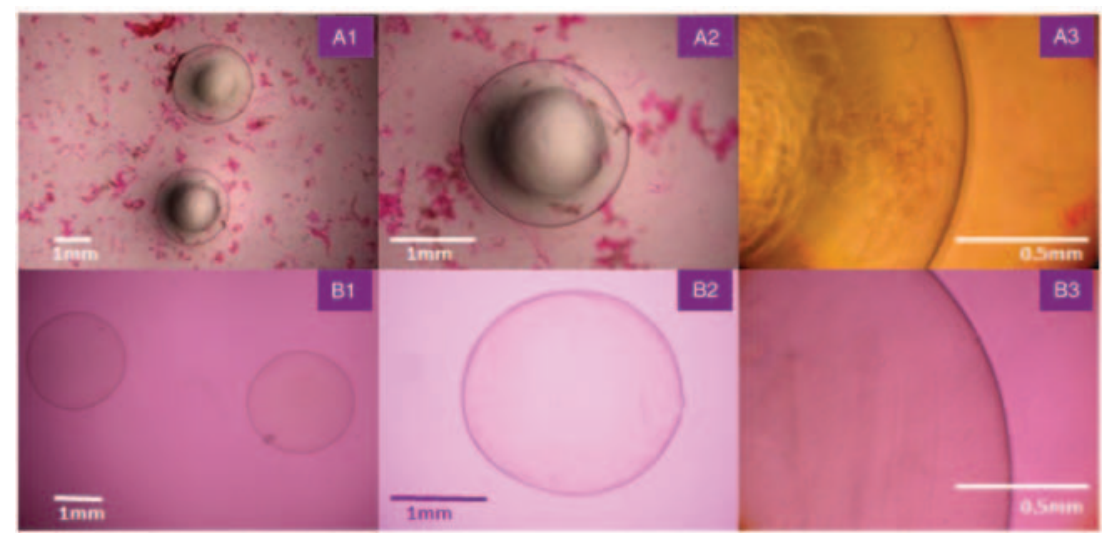

Figure 1. Optical microscopy images taken at pH 5.0 of microcapsules: (A1-A3) kappacarrageenan and (B1-B3) iota-carrageenan $(1.5 \times, 4 \times, 5 \times)$. 
have one anionic group per glucosic unit, producing a more compact and resistant capsule in comparison with kappa-carrageenan which has a lower degree of substitution (one anionic group per two glucosic unit).

The capsules alginate/iota-carrageenan were produced by extruding from a mixture of the two polyanions into a gelling agent $\left(\mathrm{CaCl}_{2}\right)$ and antigelling agent $(\mathrm{NaCl})$ [35]. According to optical microscope observations, the capsules performed exhibited spherical shape, thin, and smooth surface and revealed good stability in PBS and in culture medium (Figure 1). The diameter of the solid capsules (non-liquefied) was $\sim 2.0 \mathrm{~mm}$, while the average diameters of the liquefied capsules were $2.3 \mathrm{~mm}$. The increase in diameter in liquefied capsules is due to the enhanced swelling of the capsules [18]. The citrate, a sequestering agent, generates a strong bond between calcium ions and non-gelling sodium or potassium ions. The decrease of the $\mathrm{Ca}^{2+}$ bound between the alginate chains increases the swelling pressure inside the capsule, modifying the original diameter $[1,16]$.

The capsules obtained with different iota-carrageenan and alginate ratios and different $\mathrm{pHs}$ showed similar size, shape and stability in PBS and culture medium (Figure 2). However, the capsules obtained at $\mathrm{pH}$ 5.0 exhibited a smoother membrane and better handling properties in comparison with capsules obtained at $\mathrm{pH}$ 6.0. In previous studies, the $\mathrm{pH}$ of a solution was used to modulate the polyelectrolyte membranes. For instance, the cationic polymer chitosan is soluble at low $\mathrm{pH}$, but its solubility decreases as alkaline $\mathrm{pH}$ is approached. Moreover, the micropores of chitosan membrane capsule assume minimum dimensions at low $\mathrm{pH}$, but at about $\mathrm{pH} 6.0$ and higher, repulsive forces produce the pores to open up and the membrane permeation to rise.

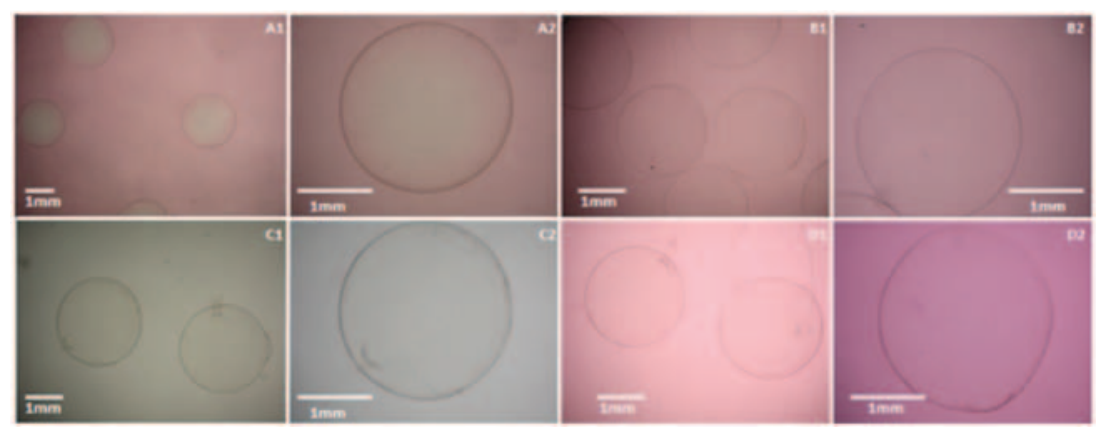

Figure 2. Optical microscopic images of solid capsules with different polymer ratios and at different $\mathrm{pH}$ : (A1-A2) microcapsules from sodium alginate/iota-carrageenan (30/70) at $\mathrm{pH} 5$; (B1-B2) microcapsules were obtained at $\mathrm{pH} 6$; (C1-C2) microcapsules from (50/50) at $\mathrm{pH} 5$; and (D1-D2) microcapsules obtained at $\mathrm{pH}$ 6. The microcapsules (A, B, and D) were dyed with eosin for observation $(1 \times, 1.5 \times, 4 \times)$. 
Previous studies showed that $\mathrm{NaCl}$ is one of the factors that determines membrane permeability as well as surface topology [35]. The sodium ions control the initial stages of complex formation. The negative charges of the reacting polymers suppress the reaction of calcium ions with the polyanion matrix. Therefore, by increasing the ratio of $\mathrm{Na}^{+}$to $\mathrm{Ca}^{2+}$ for a given polyanion mixture, it is possible to obtain a wrinkle-free surface [2].

The mechanical stability of microcapsules is a major concern in the design of cell immobilization for therapeutic devices where good mechanical stability is needed to prolong in vivo function [36]. The short-term stability had similar numbers of ruptured capsules for all the systems (Figure 3 ). The capsules produced using a mixture 50/50 sodium alginate/ iota-carrageenan of the polymers exhibited lower stability in the mechanical study ( $\pm 10 \%$ more of ruptured capsules) compared to capsules formed using 30/70 SA-IC polymers. The increase in the iota-carrageenan content of this formulation produced higher amounts of ionic sulfate groups that repel each other and contribute for the molecules being highly extended. The gradual substitution of alginate (a rigid polymer) with carrageenan (a flexible polymer) provided the flexibility required to adapt to the varying stress of tidal and wave motion caused by the agitation [37,38].

In the first $6 \mathrm{~h}$, liquefied and solid (non-liquefied) 50/50 SA-IC capsules, presented similar behavior (Figure 4). However, the 30/70 SA-IC composition had greater mechanical stability for that time period. This suggests that the decreasing stability is caused by the swelling effect related to the treatment with sodium citrate, which affects the capsules with higher

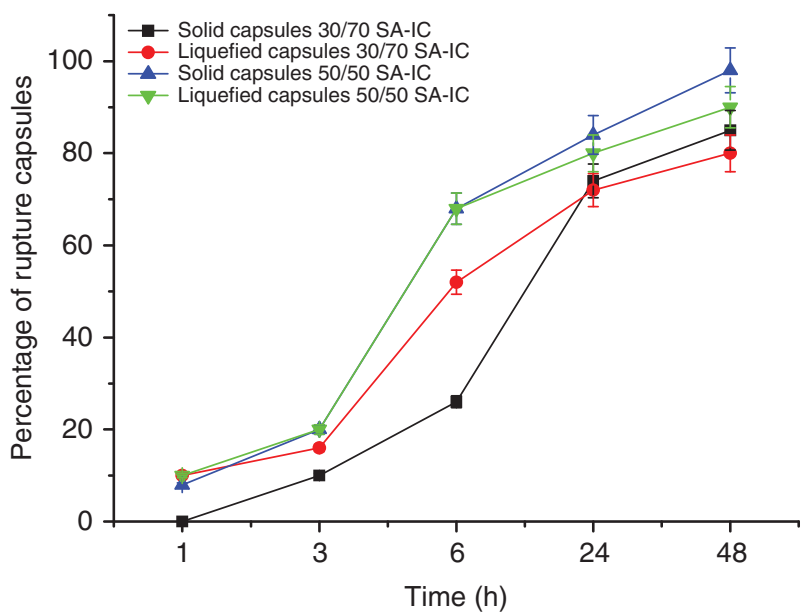

Figure 3. Percentage of ruptured microcapsules, corresponding to different sodium alginate/iota-carrageenan ratios as a function of time. 
concentration of alginate. After $24 \mathrm{~h}$, rupturing of both $30 / 70$ and 50/50 non-liquefied capsules increased, which could be related to the mass transfer of PBS through the capsule membrane. It is known that mass transfer is greater in liquefied capsules and that equilibrium is reached faster than in the non-liquefied. However, before reaching equilibrium, the mass transfer in the non-liquefied capsule may occur predominantly from the solution to the interior of the capsules, leading to their bursting.

Solid capsules (non-liquefied) were reported to be mechanically more resistant than liquefied capsules, which was attributed to the swelling effect induced by the citrate solution during production of the liquefied capsules $[16,18,39]$. In our study, statistically significant differences were not found in the stability of solid and liquefied alginate/iota-carrageenan capsules, probably due to the structure and distribution of the mixed polymers used. Accordingly, the 30/70 sodium alginate/iota-carrageenan (solid and liquefied) capsules were selected for the posterior cell encapsulation assays.

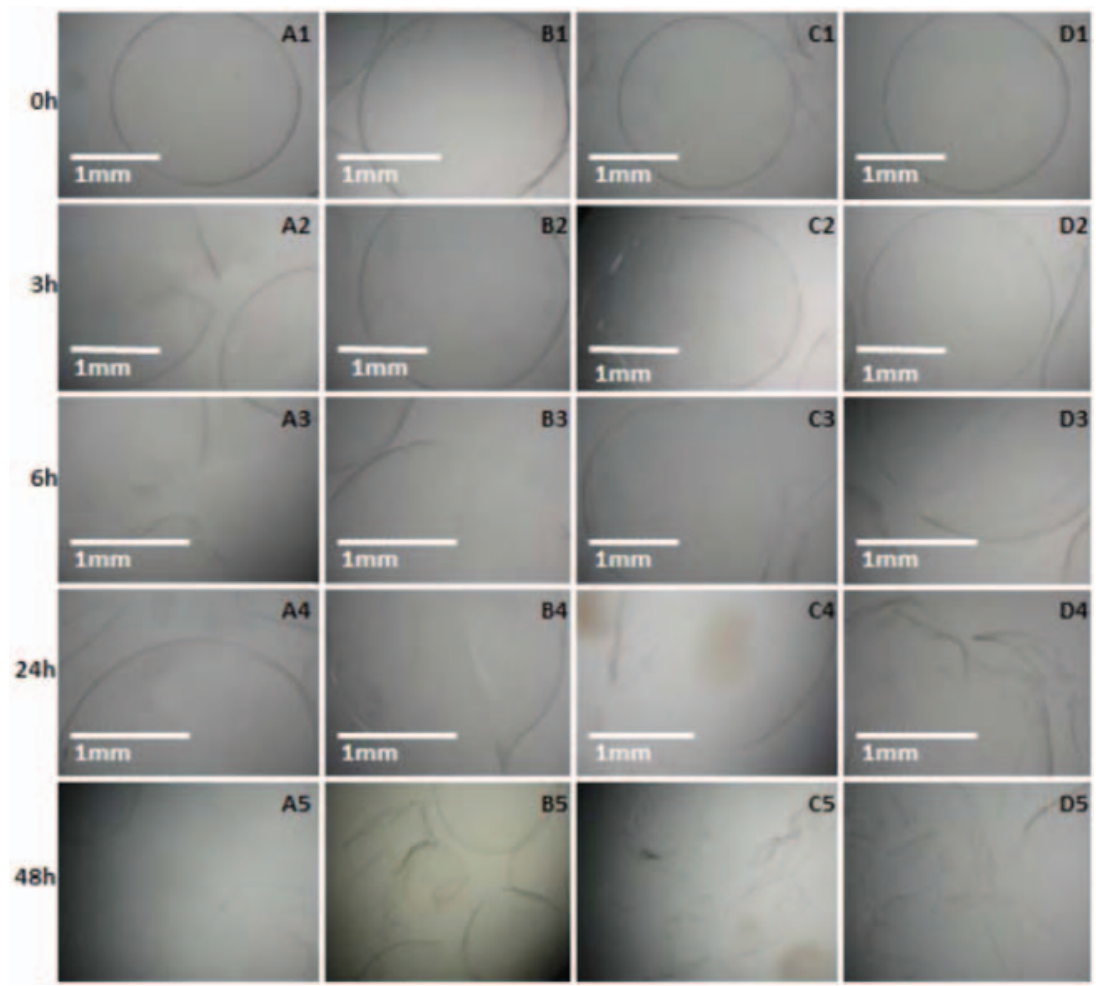

Figure 4. Optical microscopy images of the capsules at different time periods. (A) 30/70 solid capsules; (B) 30/70 liquefied capsules; (C) 50/50 solid capsules; and (D) 50/50 liquefied capsules. 
The metabolic activity and viability of the fibroblast cultured with leachables extracted from 30/70 and 50/50 sodium alginate/iota-carrageenan solid capsules were assessed using MTT test for three different periods of culture (24, 48, and $72 \mathrm{~h}$ ). Optical observations (before adding the MTT solution) revealed a good cell growth and attachment. No changes in cell morphology were detected in comparison with negative control (Figure 5), demonstrating the non-cytotoxicity of these capsule formulations. The cell viability of all the capsules was similar for all the culturing periods. However, the cell viability, determined using MTT in cells exposed to extracts of 50/50 sodium alginate/iota-carrageenan capsules, was lower compared to the cells exposed to the extract obtained from the 30/70 sodium alginate/iota-carrageenan capsules (Figure 6). The capsules with higher alginate could be producing leachable material that induce a reaction with the cells exposed to their extracts.

\section{Viability and Proliferation of Encapsulated Cells}

Based on the mechanical stability evaluation, it was decided to use the 30/70 sodium alginate/iota-carrageenan solid and liquefied capsules
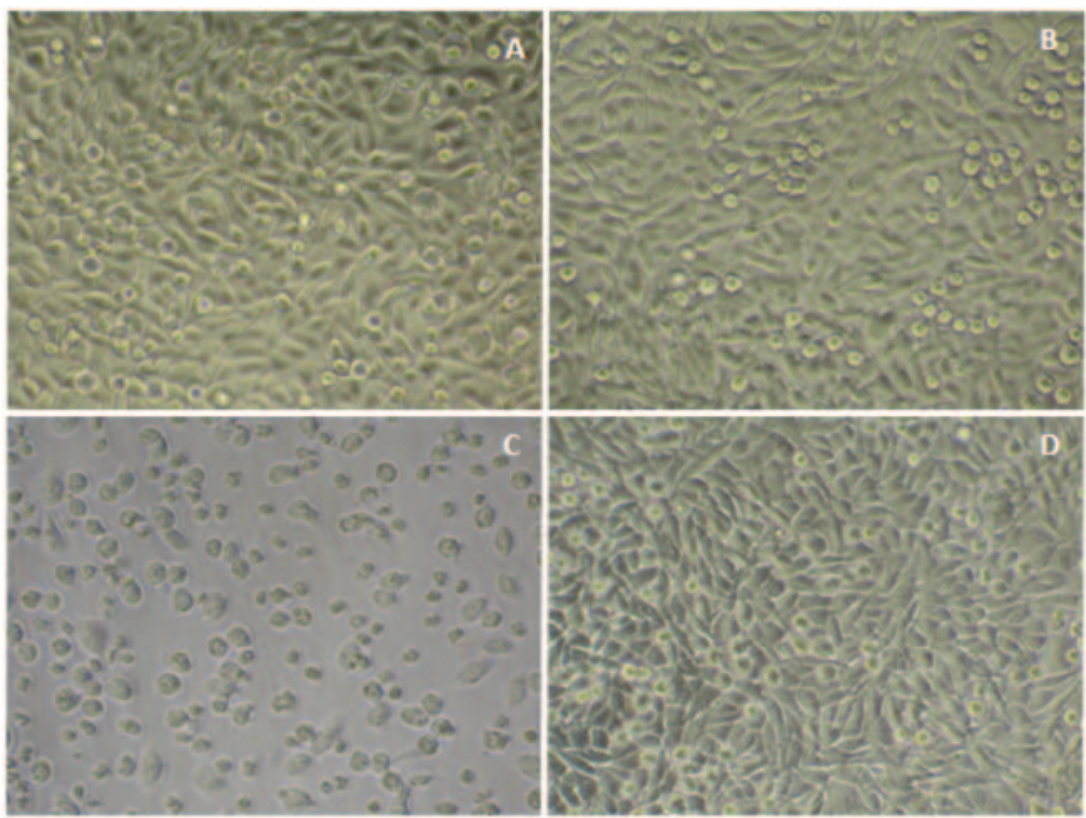

Figure 5. Morphology of fibroblasts exposed to: (A) 30/70 SA-IC capsules extracts; (B) 50/50 SAIC capsules extracts; (C) latex extracts (positive control); and (D) culture medium (negative control) incubated $72 \mathrm{~h}$ at $37^{\circ} \mathrm{C}$. 


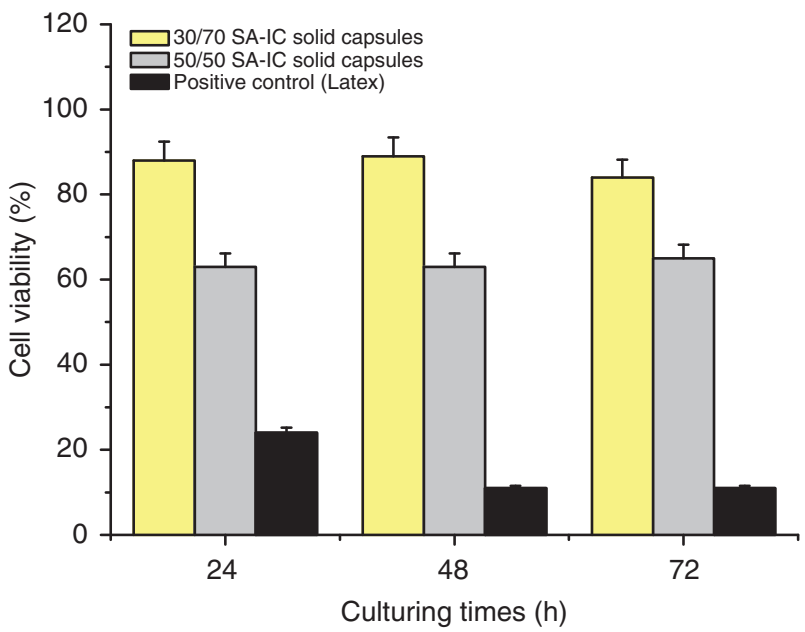

Figure 6. MTT tests of metabolic activity of the L929 fibroblasts cultured with extracts obtained from 30/70 and 50/50 SA-IC solid capsules for 24, 48, and $72 \mathrm{~h}$.

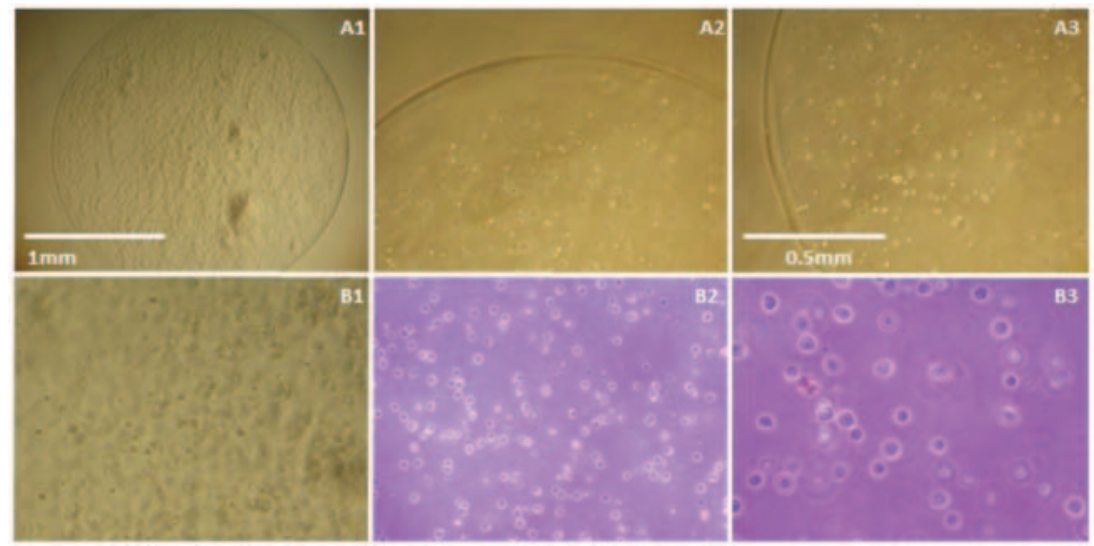

Figure 7. Optical images of encapsulated fibroblasts (within sodium alginate/iotacarrageenan (30/70) solid capsules $\mathrm{pH}$ 5.0: (A1-A3) cells within 30/70 SA-IC solid capsules

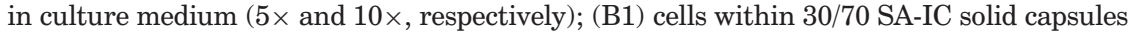
in culture medium $(20 \times)$; (B2-B3) cells within solid capsules stained with blue methylene ( $20 \times$ and $40 \times$, respectively), after $72 \mathrm{~h}$.

obtained using a chitosan solution at $\mathrm{pH}$ 5.0, for the cell encapsulation. The optical microscopy images of the capsules in culture medium and stained with methylene blue show living cells with blue colored nucleus (Figure 7). Seven days post-encapsulation, the cells exhibited similar shapes and distribution in solid and liquefied capsules and no cell 


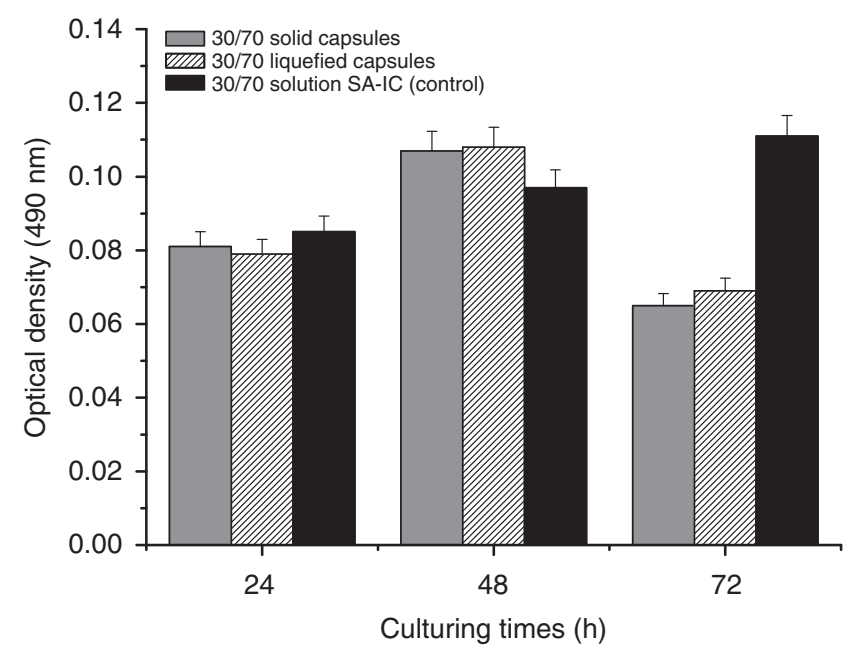

Figure 8. MTS tests of cell viability and proliferation of fibroblast entrapped within sodium alginate/iota-carrageenan capsules and in the polymeric solution SA/IC (ratio: 30/70).

aggregation. This is relevant since previous studies showed that cell aggregates could produce necrotic spaces within the capsules as a consequence of poor mass transfer $[18,40]$.

In previous studies, cells enclosed in liquefied beads improved growth profile in comparison to the cells entrapped in solid capsules [18,26]. However, in this study, the solid and liquefied capsules, using sodium alginate/iota-carrageenan as polyanions, showed a similar behavior. These results can be explained by the mixture and proportion of polymers, for example, iota-carrageenan is present in higher proportion (70\%) than sodium alginate (30\%). The iota-carrageenan confers an elastic structure to the core of the capsule, providing more flexibility as opposed to the sodium alginate that has a rigid structure [37,41].

Cellular viability and proliferation were also determined by MTS tests after culturing fibroblast cells $72 \mathrm{~h}$ in 30/70 SA-IC (solid and liquefied) capsules. A sodium alginate/iota-carrageenan (30/70) mixture with cells was also evaluated as a control. The cell viability decreased in the encapsulated cells but increased in the cell/solution mixture (Figure 8). However, the cell viability of both types of capsules did not show significant differences after $72 \mathrm{~h}$, indicating that the citrate treatment may not be relevant to improve the permeability of the capsules and hence for cell viability, using this polymeric formulation.

The cultured cell/solution did show increased cell viability with a homogeneous growth, further demonstrating the non-cytotoxicity of this 


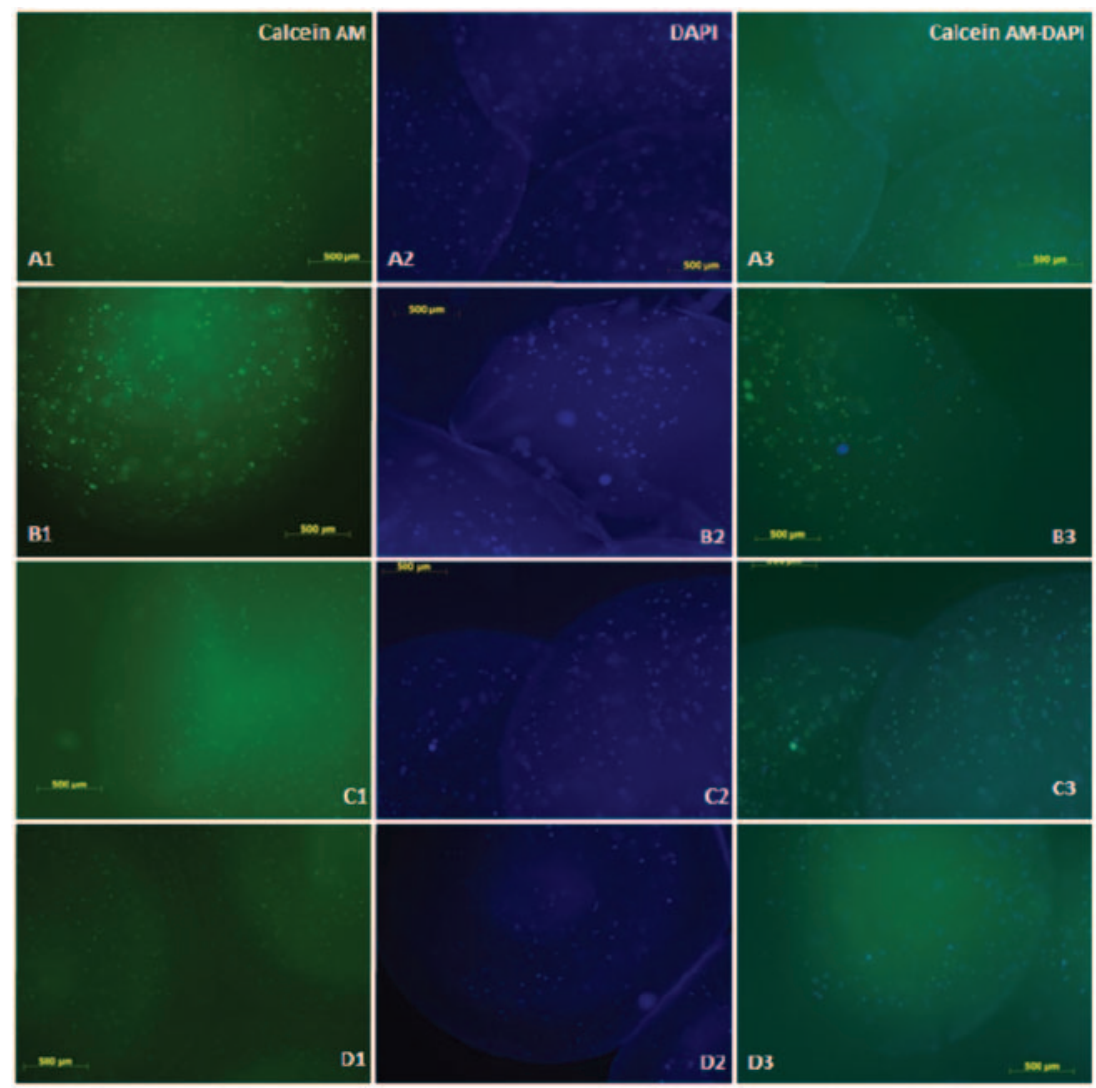

Figure 9. Fluorescent microscopic images of encapsulated fibroblasts stained with Calcein-AM and DAPI dyes after: (A1-A3) 24 h; (B1-B3) 48 h; (C1-C3) 72 h; and (D1-D3) 7 days $(5 \times)$.

mixture, confirming the MTT assays. These results also indicate that the decrease in cell viability over time in the capsules may be due to a decrease in permeability resulting from the membrane formation during the capsule preparation. In fact, the cell growth is better in cells/solution of SA-IC than in the capsules because the molecules and gases did not have to cross the membrane present in the capsule to reach the cells.

Calcein-AM fluorescent staining was used to confirm the viability of encapsulated cells (capsules 30/70, solid and liquefied); green and blue staining was evident after 7 days of cell culture (Figure 9). These results confirmed the permeability and non-toxicity of the capsule developed with sodium alginate and iota-carrageenan polymers. No differences in cell viability between encapsulated fibroblast in the solid and liquefied capsules 
were observed. The cells exhibited similar distribution and fluorescence patterns in both types of capsules. However, after 7 days, the cells in both capsules showed low fluorescence, possibly because of decreased cell viability. The results obtained indicate that Calcein-AM and DAPI were able to penetrate the alginate-carrageenan capsules containing living fibroblast cells in suspension with intact membrane, reveal cell viability within the construct. The capsules had differences in the cell viability and proliferation, as confirmed in the MTS test. Furthermore, no cell aggregates were detected by fluorescence staining (Figure 9).

\section{CONCLUSIONS}

Microcapsules developed via ionotropic gelation of sodium alginate and iota-carrageenan solutions provided stable capsules when chitosan was the main component of the capsule membrane. The mechanical properties of these capsules were influenced by the alginate/carrageenan ratio. The short-term stability evaluations indicate that the capsules with higher iota-carrageenan content are more stable and that the stability is not affected by the citrate treatment. The cells encapsulated in both solid and liquefied 30/70 SA-IC capsules maintained their viability and did not aggregate. Citrate treatment did not improve the permeability of iotacarrageenan/sodium alginate capsules made with high carrageenan $(70 \%)$ content. This new polymeric mixture of alginate with iota-carrageenan produced a promising system for cell encapsulation that may have several applications in tissue engineering and other cell therapies.

\section{ACKNOWLEDGMENTS}

One of the authors (SML) acknowledges the support of the Programme Alßan-the European Union Programme of High Level Scholarships for Latin America (scholarship no. E04M041362CO). This work was partially supported by the European STREP HIPPOCRATES (NMP3-CT-2003-505758) and by the Fundação para a Ciência e Tecnologia (project PTDC/QUI/68804/2006) and carried out under the scope of European NoE EXPERTISSUES (NMP3-CT-2004-500283).

\section{REFERENCES}

1. Orive, G., Hernandez, R.M., Gascon, A.R., Igartua, M. and Pedraz, J.L. (2003). Development and Optimisation of Alginate-PMCG-Alginate Microcapsules for Cell Immobilisation, International Journal of Pharmaceutics, 259: 57-68. 
2. Goosen, M.F.A. (2002). Microencapsulation Methods: Chitosan and Alginate. Chapter 76, In: Atala, A. and Lanza, R.P. (eds), Methods of Tissue Engineering, pp. 857-871, Academic Press, San Diego.

3. Thu, B., Bruheim, P., Espevik, T., Smidsrod, O., Soon-Shiong, P. and SkjakBraek, G. (1996). Alginate Polycation Microcapsules. I. Interaction Between Alginate and Polycation, Biomaterials, 17: 1031-1040.

4. Lee, C.S. and Chu, I.M. (1997). Characterization of Modified Alginate-PolyL-Lysine Microcapsules, Artifical Organs, 21: 1002-1006.

5. Orive, G., Hernandez, R.M., Rodriguez Gascon, A., Calafiore, R., Chang, T.M., De Vos, P. et al. (2004). History, Challenges and Perspectives of Cell Microencapsulation, Trends in Biotechnology, 22: 87-92.

6. Angelova, N. and Hunkeler, D. (1999). Rationalizing the Design of Polymeric Biomaterials, Trend in Biotechnology, 17: 409-421.

7. Kizilel, S., Garfinkel, M. and Opara, E. (2005). The Bioartificial Pancreas: Progress and Challenges. Review, Diabetes Technology and Therapeutics, 7: 968-985.

8. Bartkowiak, A. and Hunkeler, D. (2001). Carrageenan - Oligochitosan Microcapsules: Optimization of the Formation Process, Colloids and Surfaces B: Biointerfaces, 21: 285-298.

9. Patil, R.T. and Speaker, T.J. (2000). Water-based Microsphere Delivery System for Proteins, Journal of Pharmaceutical Sciences, 89: 9-15.

10. Renn, D. (1997). Biotechnology and the Red Seaweed Polysaccharides Industry: Status, Needs and Prospects, Trends in Biotechnology, 15: 9-14.

11. Tischer, P.C.S.F., Noseda, M.D., Freitas, R.A.D., Sierakowski, M.R. and Duarte, M.E.R. (2006). Effects of Iota-Carrageenan on the Rheological Properties of Starches, Carbohydrate Polymers, 65: 49-57.

12. López, A., Lázaro, N. and Marqués, A. (1997). Short Communication: The Interphase Technique: A Simple Method of Cell Immobilization in Gelbeads, Journal of Microbiological Methods, 30: 231-234.

13. Cassidy, M.B., Leung, K.T., Lee, H. and Trevors, J.T. (1995). Survival of LacLux Marked Pseudomonas aeruginosa UG2Lr Cells Encapsulated in k-Carrageenan and Alginate, Journal of Microbiological Methods, 23: 281-290.

14. Cassidy, M.B., Lee, H. and Trevors, J.T. (1997). Short Communication: Survival and Activity of Lac-Lux, Marked Pseudomonas aeruginosa UG2Lr Cells Encapsulated in k-Carrageenan Over Four Years at $4^{\circ} \mathrm{C}$, Journal of Microbiological Methods, 30: 167-170.

15. Orive, G., Ponce, S., Hernández, R.M., Gascón, A.R., Igartua, M. and Pedraz, J.L. (2002). Biocompatibility of Microcapsules for Cell Immobilization Elaborated with Different Type of Alginates. Biomaterials, 23: 3825-3831.

16. Thu, B., Bruheim, P., Espevik, T., Smidsrød, O., Soon-Shiong, P. and SkjakBræk, G. (1996). Alginate Polycation Microcapsules. II. Some Functional Properties, Biomaterials, 17: 1069-1079. 
17. Bartkowiak, A. and Hunkeler, D. (2000). Alginate-Aligochitosan Microcapsules II. Control of Mechanical Resistance and Permeability of the Membrane, Chemistry of Materials, 12: 206-212.

18. Orive, G., Hernandez, R.M., Gascon, A.R., Igartua, M. and Pedraz, J.L. (2003). Survival of Different Cell Lines in Alginate-Agarose Microcapsules, European Journal of Pharmaceutical Sciences, 18: 23-30.

19. Ribeiro, A.J., Neufeld, R.J., Arnaud, P. and Chaumeil, J.C. (1999). Microencapsulation of Lipophilic Drugs in Chitosan-coated Alginate Microspheres, International Journal of Pharmaceutics, 187: 115-123.

20. Krajewska, B. (2005). Membrane-based Processes Performed with Use of Chitin/Chitosan Materials: Review, Separation and Purification Technology, 41: $305-312$.

21. Tuzlakoglu, K., Alves, C.M., Mano, J.F. and Reis, R.L. (2004). Production and Characterization of Chitosan Fibers and 3-D Fiber Mesh Scaffolds for Tissue Engineering Applications, Macromolecular Bioscience, 4: 811-819.

22. Bejugam, N.K., Sou, M., Uddin, A.N., Gayakwad, S.G. and D'Souza, M.J. (2008). Effect of Chitosans and Other Excipients on the Permeation of Ketotifen, FITC-Dextran, and Rhodamine 123 Through Caco-2 Cells, Journal Bioactive and Compatible Polymers, 23: 187-202.

23. Alves, N.M. and Mano, J.F. (2008). Chitosan Derivatives Obtained by Chemical Modifications for Biomedical and Environmental Applications, International Journal of Biological Macromolecules, 43: 401-414.

24. Zheng, Z., Wei, Y., Wang, G., Ao, A.W.Q., Gong, Y. and Zhang, X. (2009). Surface Properties of Chitosan Films Modified with Polycations and Their Effects on the Behavior of PC12 Cells, Journal of Bioactive and Compatible Polymers, 24: 63-82.

25. Rha, C., Rodriguez-Sanchez, D. and Kienzle-Sterzer, C. (1984). Novel Applications of Chitosan, In: Colwell, R.R., Pariser, E.R. and Sinskey, A.J. (eds), Biotechnology of Marine Polysaccharides, pp. 283-311, Hemisphere Publishing, Washington, DC.

26. Peirone, M., Ross, C.J., Hortelano, G., Brash, J.L. and Chang, P.L. (1998). Encapsulation of Various Recombinant Mammalian Cell Types in Different Alginate Microcapsules, Journal of Biomedical Materials Research, 42: 587-596.

27. Mendes, S.C., Reis, R.L., Bovell, Y.P., Cunha, A.M., van Blitterswijk, C.A. and de Bruijn, J.D. (2001). Biocompatibility Testing of Novel Starch-based Materials with Potential Application in Orthopaedic Surgery: A Preliminary Study, Biomaterials, 22: 2057-2064.

28. Zhang, Z. and Feng, S.-S. (2006). The Drug Encapsulation Efficiency, in vitro Drug Release, Cellular Uptake and Cytotoxicity of Paclitaxel-loaded Poly(Lactide)-Tocopheryl Polyethylene Glycol Succinate Nanoparticles, Biomaterials, 27: 4025-4033. 
29. Salgado, A.J., Coutinho, O.P. and Reis, R.L. (2004). Novel Starch-based Scaffolds for Bone Tissue Engineering: Cytotoxicity, Cell Culture, and Protein Expression, Tissue Engineering, 10: 465-474.

30. Salgado, A.J., Gomes, M.E., Chou, A., Coutinho, O.P., Reis, R.L. and Hutmacher, D.W. (2002). Preliminary Study on the Adhesion and Proliferation of Human Osteoblasts on Starch-based Scaffolds, Materials Science and Engineering C-Biomimetic and Supramolecular Systems, 20: 27-33.

31. Cho, J., Heuzey, M.-C., Bégin, A. and Carreau, P.J. (2005). Physical Gelation of Chitosan in the Presence of $\beta$-Glycerophosphate: The Effect of Temperature, Biomacromolecules, 6: 3267-3275.

32. Chenite, A., Buschmann, M.D., Wang, D., Chaput, C. and Kandani, N. (2001). Rheological Characterisation of Thermogelling Chitosan/GlycerolPhosphate Solutions, Carbohydrate Polymers, 46: 39-47.

33. Bartkowiak, A. and Hunkeler, D. (1999). Alginate-Oligochitosan Microcapsules: A Mechanistic Study Relating Membrane and Capsule Properties to Reaction Conditions, Chemistry of Materials, 11: 2486-2492.

34. Vandenberg, G.W., Drolet, C., Scott, S.L. and de la Noue, J. (2001). Factors Affecting Protein Release from Alginate-Chitosan Coacervate Microcapsule During Production and Gastric/Intestinal Simulation, Journal of Controlled Release, 77: 297-307.

35. Wang, T.G. (2002). Microencapsulation Methods: PMCG Capsules, In: Atala, A. and Robert P. Lanza (eds), Methods of Tissue Engineering, Chap. 75, pp. 841-855, Academic Press.

36. Van Raamsdonk, J.M. and Chang, P.L. (2000). Osmotic Pressure Test: A Simple, Quantitative Method to Assess the Mechanical Stability of Alginate Microcapsules, Journal of Biomedical Materials Research, 54: 264-271.

37. Xu, J.B., Bartley, J.P. and Johnson, R.A. (2003). Preparation and Characterization of Alginate-Carrageenan Hydrogel Films Crosslinked Using Water-soluble Carbodiimide (WSC), Journal of Membrane Science, 218: 131-146.

38. Draget, K.I., Skjåk-Bræk, G. and Smidsrød, O. (1997). Alginate Based New Materials, International Journal of Biological Macromolecules, 21: 47-55.

39. Orive, G., Hernández, R.M., Gascón, A.R., Igartua, M., Rojas, A. and Pedraz, J.L. (2001). Microencapsulation of an Anti-VE-Cadherin Antibody Secreting 1B5 Hybridoma Cells, Biotechnology and Bioengineering, 76: 285-294.

40. Shen, B.Q., Greenfield, P.F. and Reid, S. (1994). Hybridoma Cells in a Protein-free Medium within a Composite Gel Perfusion Bioreactor, Cytotechnology, 16: 51-58.

41. Stancioff, D.J. and Stanley, N.F. (1996). Carrageenans: Versatile Food Ingredients, Foods and Food Ingredients Journal of Japan, 167: 37-47. 